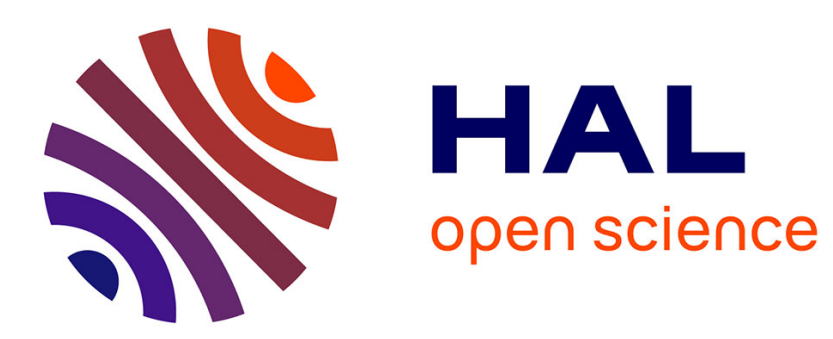

\title{
Adult peroxisomal acyl-CoA oxidase deficiency with cerebellar and brainstem atrophy
}

Sacha Ferdinandusse, Simon Barker, Katherine Lachlan, Marinus Duran, Hans R. Waterham, Ronald J.A. Wanders, Simon Hammans

\section{To cite this version:}

Sacha Ferdinandusse, Simon Barker, Katherine Lachlan, Marinus Duran, Hans R. Waterham, et al.. Adult peroxisomal acyl-CoA oxidase deficiency with cerebellar and brainstem atrophy. Journal of Neurology, Neurosurgery and Psychiatry, 2010, 81 (3), pp.310. 10.1136/jnnp.2009.176255 . hal00552782

\section{HAL Id: hal-00552782 \\ https://hal.science/hal-00552782}

Submitted on 6 Jan 2011

HAL is a multi-disciplinary open access archive for the deposit and dissemination of scientific research documents, whether they are published or not. The documents may come from teaching and research institutions in France or abroad, or from public or private research centers.
L'archive ouverte pluridisciplinaire HAL, est destinée au dépôt et à la diffusion de documents scientifiques de niveau recherche, publiés ou non, émanant des établissements d'enseignement et de recherche français ou étrangers, des laboratoires publics ou privés. 


\section{Adult peroxisomal acyl-CoA oxidase deficiency with cerebellar and brainstem atrophy}

Sacha Ferdinandusse ${ }^{1}$, Simon Barker ${ }^{2}$, Katherine Lachlan ${ }^{3}$, Marinus Duran ${ }^{1}$, Hans R.

Waterham $^{1}$, Ronald J.A. Wanders ${ }^{1}$, Simon Hammans ${ }^{2}$

${ }^{1}$ Laboratory Genetic Metabolic Diseases, Academic Medical Center at the University of Amsterdam, 1105 AZ Amsterdam, the Netherlands;

${ }^{2}$ Wessex Neurological Centre, Southampton General Hospital, Southampton, UK.

${ }^{3}$ Wessex Clinical Genetics Service, Princess Anne Hospital, Southampton, UK.

Corresponding author: $\quad$ Dr. Sacha Ferdinandusse

Lab. Genetic Metabolic Diseases, F0-220

Academic Medical Center

Meibergdreef 9

1105 AZ Amsterdam

The Netherlands

Phone: +31 20 5665958/65797

Fax: +31206962596

Email: $\underline{\text { S.Ferdinandusse@amc.uva.nl }}$

Word count: 1454

Key words: fatty acid oxidation disorder, very long-chain fatty acids, peroxisomes 


\begin{abstract}
Peroxisomal acyl-CoA oxidase deficiency (formerly also called pseudoneonatal adrenoleukodystrophy) is a disorder of peroxisomal fatty acid oxidation with a severe presentation. Most patients present at birth or in early infancy, and the mean age of death was 5 years in a recently published cohort of 22 patients. Brain imaging shows a progressive leukodystrophy. We report here the first adult patients (two siblings, 52 and 55 years old) with peroxisomal acyl-CoA oxidase deficiency with a remarkably mild clinical presentation. Magnetic resonance brain imaging showed profound atrophy of the brainstem and cerebellum.
\end{abstract}


Peroxisomal acyl-CoA oxidase deficiency (MIM264470) is a disorder of peroxisomal fatty acid oxidation caused by a deficiency of straight-chain acyl-CoA oxidase (SCOX). SCOX is the first enzyme of the peroxisomal $\beta$-oxidation system and is involved in the oxidation of various fatty acids. These include very long-chain fatty acids (VLCFAs $\geq \mathrm{C} 24: 0$ ), long-chain dicarboxylic acids and polyunsaturated fatty acids, but not branchedchain fatty acids such as pristanic acid and the C27-bile acid intermediates. Accumulation of VLCFAs is the only diagnostic marker for SCOX deficiency.

The first patients with SCOX deficiency, reported $1988^{1}$, were two siblings with neonatal hypotonia, seizures, apneic spells, delayed psychomotor development, and neurologic regression after the age of 2 years. Brain imaging showed progressive white matter demyelination without cortical malformations. Following this report, a few additional cases have been described. ${ }^{2} 3456$ Recently, the clinical, biochemical and mutational findings in a cohort of 22 patients have been published. ${ }^{7}$ All patients were children with a severe clinical presentation including psychomotor retardation, but they acquired limited skills such as sitting and standing without support. Almost all patients, however, showed a progressive loss of their motor achievements and the mean age of regression was 28 months. The mean age of death was 5 years, with the oldest patient surviving till the age of 10 .

Here we describe two SCOX-deficient siblings with a remarkable clinical presentation. The male proband was aged 52 when diagnosed with SCOX deficiency. His early developmental milestones were normal. At age 10 he was noted to have scoliosis and a clumsy right hand. His gait showed progressive unsteadiness until the age of 28 , when he became wheelchair bound. He had some urinary and faecal urgency. On 
examination, at 52 years of age, he had mildly impaired cognitive function. His memory was poor, but he was well oriented and could give an adequate description of his present problems. The visual acuity in the right eye was restricted to hand movements; left eye 6/12. He had small lens opacities. Retinitis pigmentosa was observed in both fundi, more advanced in the right eye. There was no optic disc pallor. Gaze evoked nystagmus on upgaze, downgaze and lateral gaze was present. He had a slurring dysarthric speech but near normal tongue movements. He had a jerky head tremor. There was some dystonic posturing of his arms and ataxia was seen on finger nose testing. There was spastic tone in the legs, which was not present in the arms. Reflexes were symmetrical but pathologically brisk throughout. Clonus was present at both ankles with impaired heelshin testing. Plantar responses were extensor. Sensation was normal with all modalities.

Magnetic resonance brain imaging showed profound atrophy of the brainstem and cerebellum, particularly evident in the pons, and modest cerebral atrophy. No other abnormality was seen. Nerve conduction studies were normal. ERG showed a virtually absent response from either eye.

The patient's sister was 55 upon diagnosis. Her development was normal until 8 years of age when clumsiness and unsteady gait were noted. Examination, at age 55, showed cognitive impairment with disorientation in time and place. She had poor memory but could follow simple commands. She was confined to a wheelchair. She had bilateral cataracts and fundi were not visible. She had limitation of eye movement in all directions, and gaze evoked nystagmus in all directions. Her hearing was normal. She had slow tongue movements. There was preserved strength and normal tone in the arms, but markedly impaired finger-nose testing. She was unable to move any muscle group in her 
legs, but reflexes were within normal limits. Plantar responses were extensor. There was normal sensation with all modalities.

The MRI scan of the sister also showed marked cerebellar and brainstem atrophy with modest atrophy of the cerebral hemispheres. There was no evidence of parenchymal signal abnormality (Fig 1A to C).

Because of a clinical suspicion of a peroxisomal disorder, plasma VLCFAs were measured (table 1). The level of C26:0 was increased in plasma from both the brother $(3.31 \mu \mathrm{mol} / \mathrm{L})$ and the sister $(1.59 \mu \mathrm{mol} / \mathrm{L}$; control range $0.45-1.32 \mu \mathrm{mol} / \mathrm{L})$. However, the $\mathrm{C} 26: 0 / \mathrm{C} 22: 0$ and $\mathrm{C} 24: 0 / \mathrm{C} 22: 0$ ratios were only marginally increased in the brother and even normal in the sister. Interestingly, acylcarnitine analysis in plasma revealed the presence of trace amounts of C26-carnitine, C24-carnitine and C16-dicarboxylylcarnitine. ${ }^{8}$ The level of the polyunsaturated fatty acids, including docosahexaenoic acid

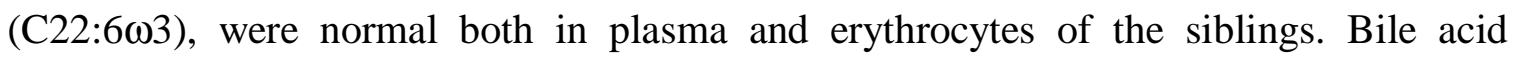
analysis in plasma as well as the analysis of pristanic and phytanic acid did not reveal any abnormalities. Organic acid profiling in urine showed increased excretion of sebacic acid (C10-dicarboxylic acid), 2-hydroxy-sebacic acid, 3-hydroxy-sebacic acid and suberic acid (C8-dicarboxylic acid). The prominent excretion of these dicarboxylic acids is characteristic for patients with a peroxisomal fatty acid oxidation disorder. ${ }^{9}$ 
Table 1 Biochemical analyses in plasma and skin fibroblasts

\begin{tabular}{|c|c|c|c|}
\hline & Brother & Sister & Range \\
\hline \multicolumn{4}{|l|}{ Plasma } \\
\hline $\mathrm{C} 26: 0^{a}$ & 3.31 & 1.59 & $0.45-1.32$ \\
\hline $\mathrm{C} 24: 0^{a}$ & 100.3 & 86.1 & $33-82$ \\
\hline $\mathrm{C} 22: 0^{a}$ & 98.0 & 98.0 & $40-119$ \\
\hline $\mathrm{C} 26 / \mathrm{C} 22$ ratio & 0.03 & 0.02 & $<0.02$ \\
\hline C24/C22 ratio & 1.02 & 0.88 & $<0.94$ \\
\hline Phytanic acid $^{a}$ & 3.8 & 3.4 & $0-9$ \\
\hline Pristanic acid $^{a}$ & 0.8 & 0.4 & $0-3.1$ \\
\hline \multicolumn{4}{|l|}{ Erythrocytes } \\
\hline $\mathrm{DHA}^{b}$ & 23.6 & 19.6 & $15.2-37.6$ \\
\hline \multicolumn{4}{|l|}{ Skin fibroblasts } \\
\hline SCOX activity $^{c}$ & 16 & ND & $49-151$ \\
\hline C26:0 $\beta$-oxidation ${ }^{d}$ & 590 & ND & $1,025-2,994$ \\
\hline Pristanic acid $\beta$-oxidation $^{d}$ & 1616 & ND & $691-2,178$ \\
\hline C16:0 $\beta$-oxidation ${ }^{d}$ & 2964 & ND & $1,729-5,361$ \\
\hline
\end{tabular}

${ }^{a} \mu \mathrm{mol} / \mathrm{L},{ }^{b} \mathrm{pmol} / 10^{6}$ cells, ${ }^{c} \mathrm{pmol} /\left(\min . \mathrm{mg}\right.$ protein), ${ }^{d} \mathrm{pmol} /(\mathrm{h} . \mathrm{mg}$ protein); ND, not determined. 
Subsequent investigations in cultured skin fibroblasts of the brother revealed a strongly reduced $\beta$-oxidation activity with $\mathrm{C} 26: 0$ as substrate (590 pmol/(h.mg protein); control range 1,025-2,994 pmol/(h.mg protein)) (table 1). The activities of pristanic acid and C16:0 $\beta$-oxidation were completely normal. Immunofluorescence with antibodies against the peroxisomal matrix enzyme catalase and the peroxisomal membrane protein adrenoleukodystrophy protein (ALDP) revealed peroxisomes that were increased in size and reduced in number compared to control fibroblasts. These results prompted us to measure the activity of different $\beta$-oxidation enzymes in fibroblast homogenates. SCOX activity was clearly deficient (16 pmol/(min.mg protein); control range 49-151 $\mathrm{pmol} /($ min.mg protein)), whereas normal activities were measured for branched-chain acyl-CoA oxidase, D-bifunctional protein and Sterol carrier protein X (not shown). To confirm the SCOX deficiency at the molecular level, we performed mutation analysis of the ACOXI gene encoding SCOX. An apparent homozygous missense mutation, c.629G>A, was identified in DNA isolated from skin fibroblasts of the brother. The same apparent homozygous mutation was also identified in DNA isolated from lymphocytes of the sister. No material from the patients' parents, who are first cousins, was available to confirm homozygosity. The mutation c.629G>A leads to the amino acid substitution p.R210H. Immunoblot analysis with antibodies against SCOX revealed the normal presence of the $72 \mathrm{kDa}$ full-length protein and the 51 and $21 \mathrm{kDa}$ bands, the products of the proteolytical cleavage of the full-length protein, in fibroblast homogenates of the brother.

Virtually all SCOX-deficient patients die early in childhood. Up to now the oldest surviving patient with an SCOX deficiency described in the literature was a 19-year old 
Japanese boy who manifested psychomotor retardation and regression during the late infantile period and who required respiration and tube feeding since the age of $11 .^{510}$ The siblings described in this report have a remarkably mild presentation of SCOX deficiency, and are alive at 52 and 55 years of age. The brain imaging contrasts with reported findings in the literature which describe changes occurring in early childhood: initially there is signal abnormality in cerebellar white matter, the middle cerebellar peduncles and in brainstem tracts, with vermian atrophy; later abnormal signal appears in the pyramidal tracts more superiorly in the brainstem, and in the posterior limb of the internal capsule; the parieto-occipital periventricular white matter and splenium of corpus callosum is then involved with later spread to frontal white matter. ${ }^{345}$

In agreement with the relatively mild clinical presentation, the biochemical parameters in skin fibroblasts of the brother were only mildly abnormal. The residual C26:0 $\beta$ oxidation activity was one of the highest of a cohort of 20 SCOX-deficient skin fibroblasts available in our laboratory (590 compared to a patient range of 161-598 pmol/(h.mg protein)). This suggests that the SCOX protein displays some residual activity. This is difficult to ascertain in skin fibroblasts because the other peroxisomal acyl-CoA oxidase, which primarily handles branched-chain substrates, has been shown to display also low activity towards straight-chain fatty acids. ${ }^{11}$ However, the amino acid substitution identified in the siblings does not affect the catalytic unit or the co-factor (FAD) binding site when analyzing the crystal structure of rat $\mathrm{SCOX},{ }^{12}$ in contrast to almost all the other amino acid substitutions described in SCOX-deficient patients.

In conclusion, we present the first adult patients with peroxisomal acyl-CoA oxidase deficiency. This diagnosis should be considered even when imaging findings are not 
typical of a peroxisomal disorder, and may also be suggested by abnormal VLCFAs in patients clinically atypical of the adrenoleukodystrophy / myeloneuropathy spectrum. 


\section{ACKNOWLEDGMENTS}

We thank P.A.W. Mooyer, C. Dekker, H. Rusch, S. Denis, W. Smit and E.M. Hogenhout for technical assistance. We thank Dr. Graham Warner for referring the patient to us. This work was supported by the Netherlands Organisation for Scientific Research (NWO, grant 916.46.109) and the FP6 European Union Project 'Peroxisomes' (Grant number: LSHG-CT-2004512018). 


\section{REFERENCES}

1. Poll-The BT, Roels F, Ogier H, et al. A new peroxisomal disorder with enlarged peroxisomes and a specific deficiency of acyl-CoA oxidase (pseudo-neonatal adrenoleukodystrophy). Am J Hum Genet 1988;422-34.

2. Watkins PA, McGuinness MC, Raymond GV, et al. Distinction between peroxisomal bifunctional enzyme and acyl-CoA oxidase deficiencies. Ann Neurol 1995;472-7.

3. Kurian MA, Ryan S, Besley GT, et al. Straight-chain acyl-CoA oxidase deficiency presenting with dysmorphia, neurodevelopmental autistic-type regression and a selective pattern of leukodystrophy. $J$ Inherit Metab Dis 2004; $105-8$.

4. Rosewich H, Waterham HR, Wanders RJ, et al. Pitfall in metabolic screening in a patient with fatal peroxisomal beta-oxidation defect. Neuropediatrics 2006;95-8.

5. Suzuki Y, Iai M, Kamei A, et al. Peroxisomal acyl CoA oxidase deficiency. $J$ Pediatr 2002;128-30.

6. Carrozzo R, Bellini C, Lucioli S, et al. Peroxisomal acyl-CoA-oxidase deficiency: two new cases. Am J Med Genet A 2008;1676-81.

7. Ferdinandusse S, Denis S, Hogenhout EM, et al. Clinical, biochemical, and mutational spectrum of peroxisomal acyl-coenzyme A oxidase deficiency. Hum Mutat 2007;904-12.

8. Rizzo C, Boenzi S, Wanders RJ, et al. Characteristic acylcarnitine profiles in inherited defects of peroxisome biogenesis: a novel tool for screening diagnosis using tandem mass spectrometry. Pediatr Res 2003;1013-8.

9. Korman SH, Mandel HGutman A. Characteristic urine organic acid profile in peroxisomal biogenesis disorders. J Inherit Metab Dis 2000;425-8.

10. Funato M, Shimozawa N, Nagase T, et al. Aberrant peroxisome morphology in peroxisomal beta-oxidation enzyme deficiencies. Brain Dev 2006;287-92.

11. Vanhove GF, Van Veldhoven PP, Fransen M, et al. The CoA esters of 2-methylbranched chain fatty acids and of the bile acid intermediates di- and trihydroxycoprostanic acids are oxidized by one single peroxisomal branched chain acyl-CoA oxidase in human liver and kidney. J Biol Chem 1993;10335-44.

12. Nakajima Y, Miyahara I, Hirotsu K, et al. Three-dimensional structure of the flavoenzyme acyl-CoA oxidase-II from rat liver, the peroxisomal counterpart of mitochondrial acyl-CoA dehydrogenase. J Biochem (Tokyo) 2002;365-74. 


\section{FIGURE LEGEND}

Figure 1. Axial T2 weighted images at the level of the middle cerebellar peduncles (A) and the lateral ventricles (B), and midline sagittal T1 weighted image (C). There is marked atrophy of the cerebellum, middle cerebellar peduncles and brainstem, with modest atrophy of the cerebrum. No parenchymal signal abnormality is seen. 


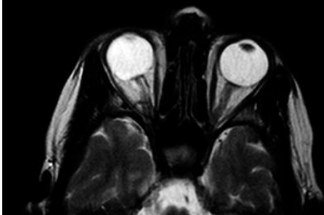

4.
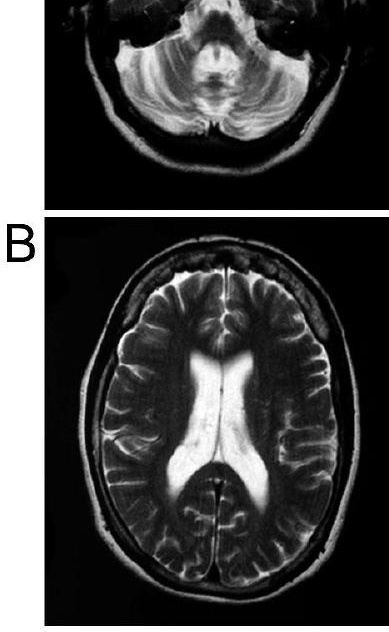

C

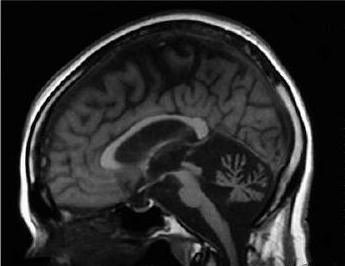

